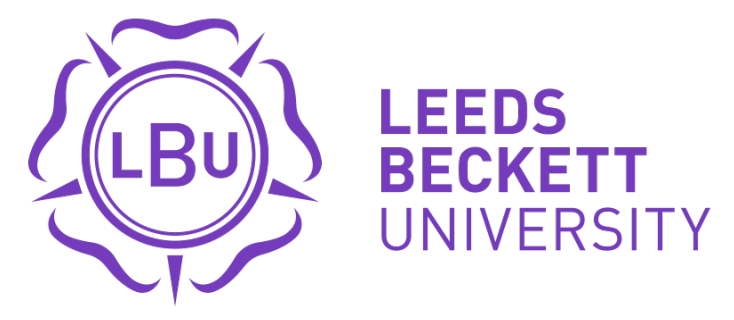

Citation:

Truelove, I (2020) Bringing the Blockchain to Life: Or how I learned to stop worrying and love the algorithm. In: EVA London 2020: Electronic Visualisation \& the Arts. BCS Learning and Development Ltd, pp. 236-238. ISBN 9781780175386 DOI: https://doi.org/10.14236/ewic/eva2020.42

Link to Leeds Beckett Repository record:

https://eprints.leedsbeckett.ac.uk/id/eprint/7058/

Document Version:

Book Section (Published Version)

Creative Commons: Attribution 4.0

(C) Truelove.

The aim of the Leeds Beckett Repository is to provide open access to our research, as required by funder policies and permitted by publishers and copyright law.

The Leeds Beckett repository holds a wide range of publications, each of which has been checked for copyright and the relevant embargo period has been applied by the Research Services team.

We operate on a standard take-down policy. If you are the author or publisher of an output and you would like it removed from the repository, please contact us and we will investigate on a case-by-case basis.

Each thesis in the repository has been cleared where necessary by the author for third party copyright. If you would like a thesis to be removed from the repository or believe there is an issue with copyright, please contact us on openaccess@leedsbeckett.ac.uk and we will investigate on a case-by-case basis. 


\title{
Bringing the Blockchain to Life: Or how I learned to stop worrying and love the algorithm
}

\author{
Ian Truelove \\ Leeds School of Arts \\ Leeds Beckett University \\ Broadcasting Place \\ Leeds LS2 9EN, UK \\ i.a.truelove@leedsbeckett.ac.uk
}

\section{INTRODUCTION}

At EVA 2019, I made a case for the value of the human hand in digital art, and argued that the algorithm, devoid of humanity, was inferior. As a result of healthy debate following my presentation, I have now completely shifted my position and, through the development of a new series of artworks, I have learned to stop worrying and love the algorithm. In this paper, I document the development of my thinking and working over the last twelve months, I highlight the capacity for algorithm and data driven visualisation to embody and convey human concerns that are relevant to today, and I detail how my artworks pose questions about the commercial measurement of art.

Shortly after EVA 2019 had opened my mind up to the value of algorithmic art I paid a visit to Prague National Gallery's Trade Fair Palace. Whilst contemplating the wealth of Czech art on display, a particular painting caught my eye. Something about it called out to me and I found myself absorbed in its graphic elegance. The painting was Line no. 50 by Zdeněk Sýkora, and my subsequent research into this artist revealed why I was drawn to this painting. Sýkora was an early pioneer of algorithmic art, and Line no. 50 was a painting based on computer generated curves. The initial experiments with algorithmic art that I had started shortly after EVA 2019 had been following a similar line of enquiry to Sýkora and it was this resonance with my own work that my brain had felt when I set eyes on Line no. 50 in Prague. Energised by the discovery of this kindred spirit, my shift from human painter to algorithmic artist was complete.

\section{HOGARTH AND THE SERPENTINE LINE}

Hogarth returns to his conception of the form of objects in terms of a surface corresponding to a shell of lines. Lines are (1) straight and (2) circular (curving), and there are also (3) the waving line (composed of contrasting curves in a plane) and (4) the serpentine line (waving and winding, or twisting, in space). The waving line is the "line of beauty" and the serpentine line is the "line of grace". These two lines are the lines most varied in form, and they contribute most to producing beauty. (Davis 2010)

In his 1753 book 'The Analysis of Beauty', William Hogarth outlined his thoughts about the aesthetics of curved lines. In my previous hand-driven painting, I expended a great deal of effort chasing the serpentine 'line of grace', using it to guide my human-judgements as I pushed pixels around my iPad screen. In the serpentine lines that make up Sykora's paintings I saw the same pursuit of this line of grace. In my initial algorithmic experiments, I found myself once again pursuing this line, not through brush-strokes, but through an iterative process of trial and error programming.

\section{THE BLOCKCHAIN AND MERKLE TREES}

The blockchain is an indelible ledger of transactions encoded in distributed digital copies. It is impossible to change anything on these copies without someone noticing, making the blockchain trustworthy enough to support a currency. The most famous of these blockchain-enabled cryptocurrencies is Bitcoin. Hidden in the freely downloadable record of Bitcoin's historical daily financial dealings are traces of a new capitalist aesthetic. 


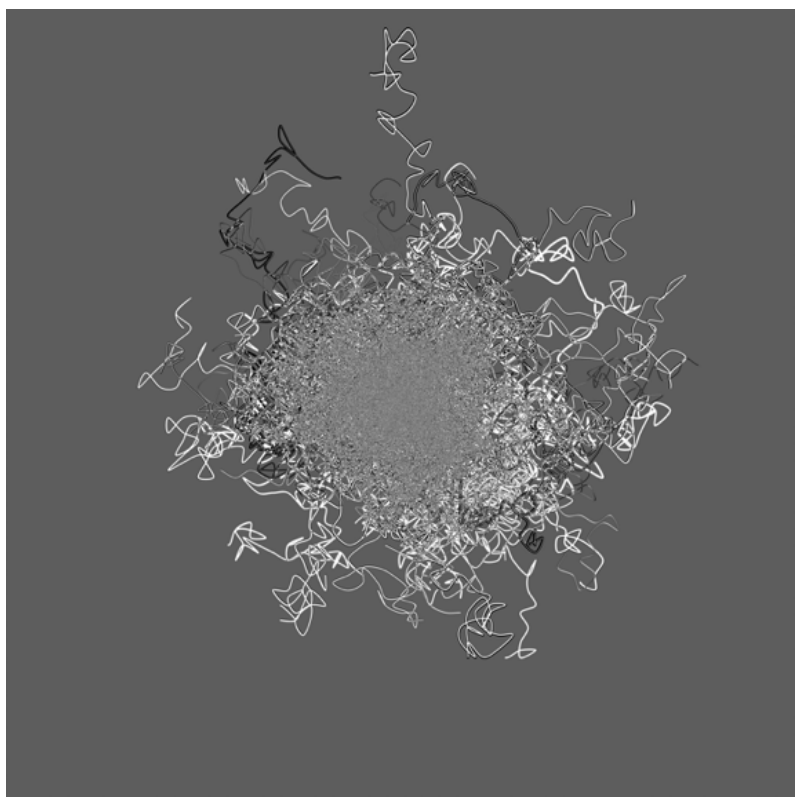

Figure 1: July 18th 2013, \$91.

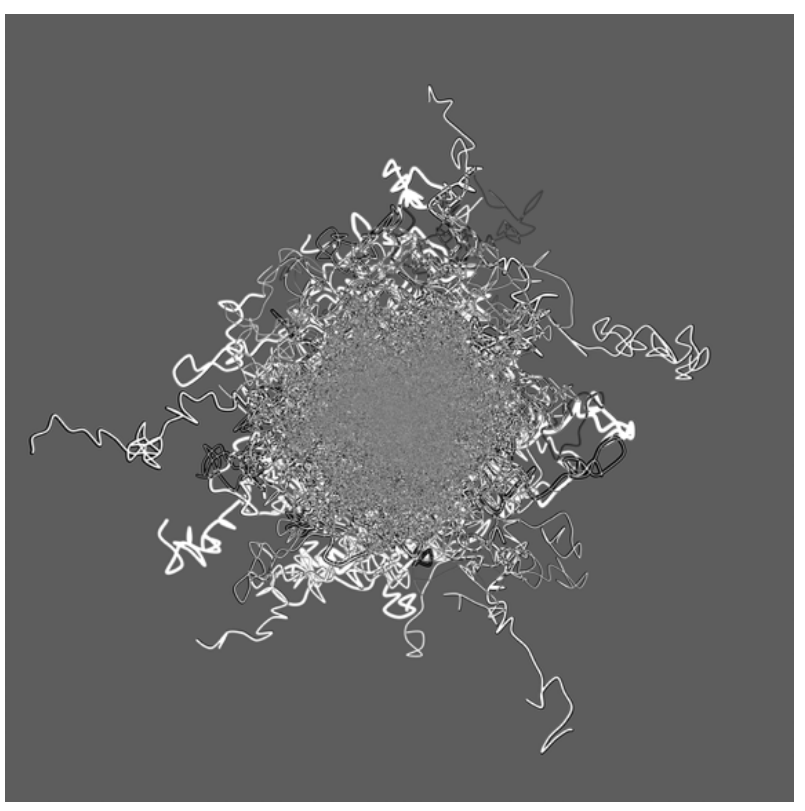

Figure 2: July 18th 2015, \$275.

One part of the blockchain puzzle, derived from each chunk of transactions, is the merkle tree root. Merkle trees are a method for crunching complex data into a unique 64character hash. Hashes from individual transactions are iteratively hashed until one hash remains, providing a unique encoding for one block in the chain. This hash is impossible to reverse engineer but is the authentic stamp of that block. Each as unique as the structure of an individual snowflake or the pattern of a human fingerprint, merkle tree roots are the shape of one block in the chain. However, a string of 64 characters is not as interesting to look at as a fingerprint or a snowflake, and so I began writing algorithms to visualise this data, with a view to bringing the blockchain into the optical realm.

Inspired by Sýkora and guided by Hogarth, I used the open coding platform, Processing, to develop a formula that took the merkle tree roots generated on a particular day and turn them into twisting serpentine lines. The thickness of the lines was determined, in part, by the price in dollars of one Bitcoin on that particular date. Visualisations of more recent dates - when Bitcoin was worth many dollars - are bulbous, and more distant dates when Bitcoin was worth very little - are scratchy. For each day of historical Bitcoin data, a single image was generated, each a composite of the swirling merkle tree roots that the blockchain spawned that day.

\section{THE BLOCKCHAIN AND THE ART MARKET}

The Blockchain has garnered the interest of the commercial art market as it can be used to authenticate purely digital artworks. Services such a Verisart enable provenance to be established for non-physical artworks, and digital art can be bought and sold without it ever being printed out. As part of my research, I have used Verisart to encode a series of my Merkle-tree artworks, probing the commercial issues that surround digital art. The title of each artwork is made up from the data that the Bitcoin data used to drive the algorithm, plus the price of one Bitcoin on that date (e.g. July 18th $2019, \$ 10666)$. The title is not the price of the artwork, but it could be. Images generated from older data, with their thinner and scratchier lines, reflect the lower price of a Bitcoin in the past, and could sell for less. The fatter lines of the later artworks, engorged by the higher price of Bitcoin at that time, could sell for more. My interest is not in exploiting the commercial value of my artwork, but asking questions about the monetary measures of art.

\section{CONCLUSION AND FUTURE FOCUS}

As part of the testing of this research, in November 2019, three artworks were exhibited in printed form at Gallery House in central Leeds. However, the one metre square canvas inkjet prints presented to the public are not the originals: the original artworks are digital and are therefore non-physical. The authenticity of each digital original is, nonetheless, re-encoded in the Blockchain via Verisart, affording trustworthy provenance and potential sales of nothing real. The certificates of authenticity that accompanied each printout at the exhibition served as proof, not of the value of a printout, but of the value of its infra-thin digital root. 


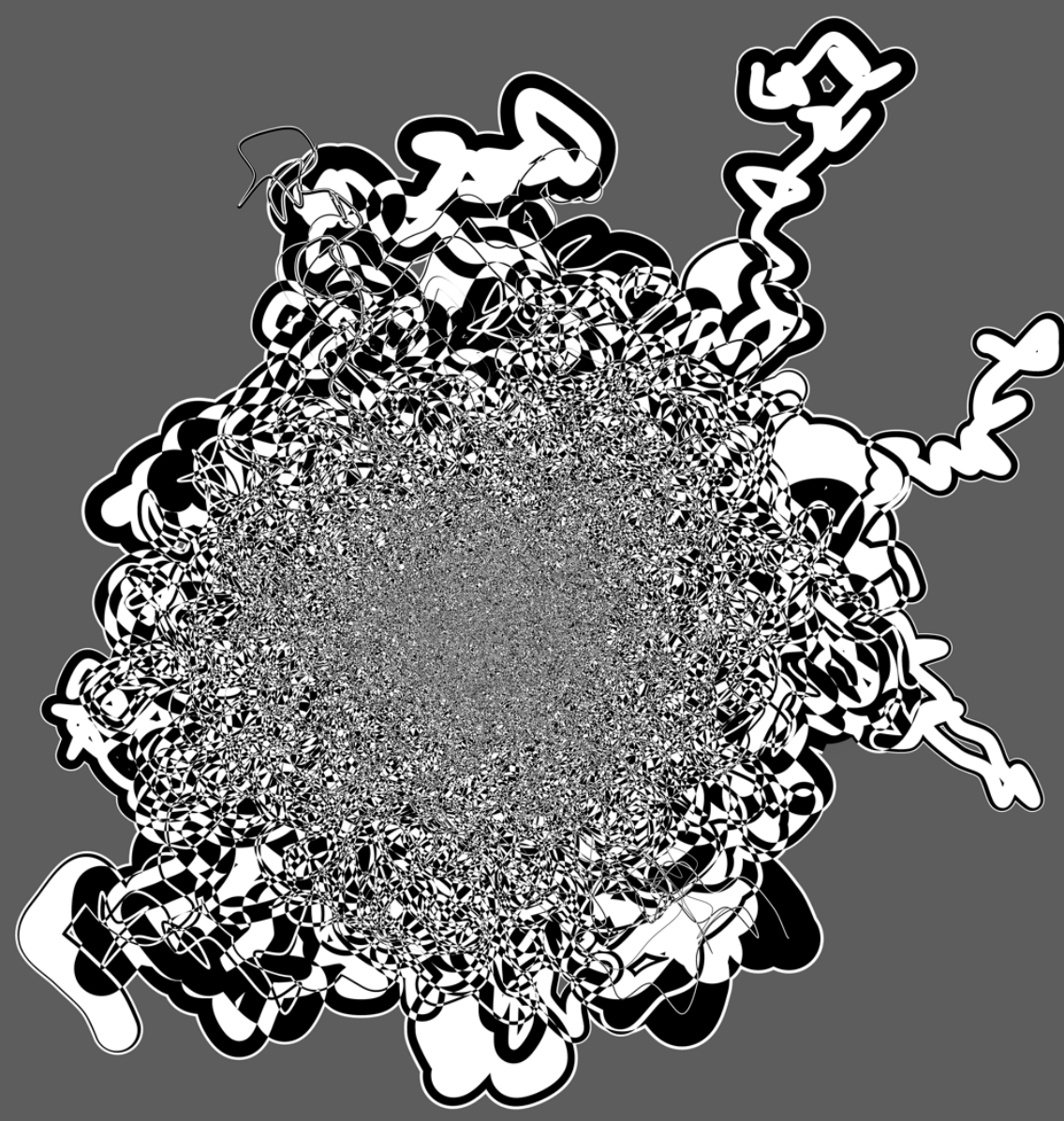

Figure 3: July 18th 2019, \$10666.

Encouraged by the positive reaction to the exhibition, plans are afoot to expand the research programme. At the time of writing, the relationship between the age-old safe financial bet, gold, and the cryptographic certainty inherent in Bitcoin is forming the basis of a new set of artworks, crafted from real gold. I am also exploring the potential for bringing my Bitcoin artworks to new audience via augmented reality. It is anticipated that a selection of these new artworks will be available to view at the EVA 2020 conference.

\section{REFERENCES}

Davis, C. (2010) In: Hogarth, W. (1753) The Analysis of Beauty. London: John Reeves, London. 